\title{
$O$ fator institucional pode afetar valores e comportamentos segundo a lógica mercantilista e a dinâmica organizacional? Um estudo realizado sobre o ensino superior privado em administração
}

\author{
Shaiane Caroline Kochhann ${ }^{1}$ \\ Luis Adriano Rodrigues ${ }^{2}$ \\ Ana Elizabeth Moiseichyk ${ }^{3}$
}

Resumo: As mudanças organizacionais vêm intrigando institucionalistas e gerando a necessidade pela busca do entendimento aos desafios enfrentados pelo mundo dos negócios. É neste sentido, que, frente a um mercado cada vez mais competitivo e em constante crescimento, surge a necessidade das universidades privadas buscarem aprimorar seus métodos de ensino, bem como, se adequarem as exigências voltadas aos seus clientes e ao mercado. $\mathrm{O}$ método possui caráter quantitativo exploratório. $\mathrm{O}$ estudo foi aplicado com 216 alunos do curso de Administração, em duas universidades privadas, localizadas no interior do Rio Grande do Sul. Partindo-se do ponto vista, de que organizações possuem uma cultura própria, na qual as mantém ativas dentro do contexto mercadológico, buscou-se responder o questionamento: Os valores, princípios, a qualidade e as normas defendidas pelas instituições de ensino superior são condizentes com as expectativas dos discentes? Como objetivo geral, buscou-se identificar o posicionamento e a visão dos alunos frente a sua instituição de ensino, e com isto, averiguar de forma prática no que interfere os fatores institucionais. Como resultados, foi possível diagnosticar que Instituições de Ensino Superior Privado, usufruem de diversos fatores como valores, princípios, qualidade e as normas/padrões de conduta sobre seus negócios, onde o fator institucional se torna aparente, além de ser percebida como uma estratégia competitiva de mercado.

Palavras-chave: Ensino Superior Privado, Institucionalização, Mercantilização e Dinâmica Organizacional.

\section{The institutional factor can affect values and behaviors according to the mercantilist logic and organizational dynamics? A study on the private higher education in management}

\footnotetext{
${ }^{1}$ Mestranda em Administração. Universidade Federal de Santa Maria (UFSM). E-mail: kochhannshaiane@gmail.com

${ }^{2}$ Mestrando em Administração. Universidade Federal de Santa Maria (UFSM). E-mail: luisadriano@bol.com.br

${ }^{3}$ Doutora em Engenharia da Produção. Universidade de Santa Catarina (UFSC). E-mail: anamoiseichyk@hotmail.com
} 


\begin{abstract}
The organizational changes are intriguing institutionalists and creating the need for the search for understanding the challenges faced by the business world. It is in this sense that, compared to a market increasingly competitive and growing, there is a need of private universities seek improve their teaching methods, as well as suit the requirements facing its customers and the market. The method has exploratory quantitative character. The study was applied to 216 Administration degree students in two private universities located in the interior of Rio Grande do Sul. Starting from the point of view that organizations have their own culture, in which the active professional keeps within the market context, they sought to answer the question: the values, principles, quality and standards advocated by higher education institutions are consistent with the expectations of students? As a general objective, we sought to identify the position and view of the students in front of your school, and thus, determine in a practical way in which interferes institutional factors. As a result, it was possible to diagnose that of Private Higher Education Institutions benefit from several factors such as values, principles, quality and norms / standards of conduct of their business, where the institutional factor becomes apparent, and be perceived as a competitive strategy market.
\end{abstract}

Keywods: Private Higher Education, Institutionalization, Commodification and Organizational Dynamics.

\title{
1 INTRODUÇÃO
}

A busca pela compreensão das mudanças organizacionais, a alguns anos já vêm intrigando institucionalistas e configurando um grande desafio para o mundo dos negócios. A “institucionalização é a emergência de padrões ordenadores, estáveis, e socialmente integradores, de um contexto de atividades instáveis" (MACHADO-DA-SILVA; FONSECA; CRUBELLATE, 2005, p. 14) que buscam reestabelecer a estabilidade e a adequação dentro da dinâmica capitalista que a atual sociedade contemporânea emerge, priorizando-se continuamente o sucesso empresarial.

Ao compreender a contínua busca por parte das organizações, quanto a estabilidade e a adequação a dinâmica mercantilista, sugere-se, a necessidade de contextualizar o conceito de isomorfismo. O Isomorfismo pode ser descrito como um mecanismo de autodefesa, em que as organizações procuram estabilizar-se frente a instabilidade propiciada pelo mercado. Isto quer dizer, que as instituições ao adotarem uma postura isomórfica, passam a desenvolver e tomar decisões similares às outras organizações líderes de mercado, priorizando então a sua sobrevivência e adaptação a partir de regras aceitas e impostas pelo mercado.

Neste contexto de instabilidade, através da busca pela sobrevivência no mercado, é que se torna possível enxergar a dinâmica das organizações. Deste modo, por meio de Ferreira, 
Filho e Beltrão (2013, p.1) “a dinâmica organizacional é um processo que vem se intensificando cada vez mais nos últimos tempos e incidindo não apenas em um campo, mas em vários, tais como, nos contextos: sociais, econômicos, políticos, ambientais e institucionais; resultando em um estado permanente de vulnerabilidade por parte das empresas".

Assim, por meio deste estudo, buscou-se identificar os mecanismos de adaptação promulgados por instituições de ensino superior privado, localizadas no interior do Rio Grande do Sul. Logo, tendo em vista a adoção de medidas que priorizam o equilíbrio frente ao contexto mercadológico, é que as instituições podem introduzir atitudes tanto de adaptação como de mudança, ou seja, atitudes que busquem induzir a sobrevivência do negócio em seu contexto.

Deste modo, os valores, os princípios, a qualidade e as normas cultuadas por uma instituição de ensino superior privada podem ser determinantes, frente a estabilidade e a incorporação do negócio no mercado; onde características, crenças e atitudes defendidas e promulgadas pelas instituições de ensino, podem pontuar de forma direta e decisiva sobre a continuidade dos discentes nas devidas instituições, e com isto, incidindo diretamente sob a sobrevivência da instituição no mercado (SCHARMACH, 2009).

De forma geral, quanto as instituições de ensino privado, devido à grande concorrência existente neste segmento, muitas priorizam a integridade e a imagem do seu negócio. Partindo-se do ponto vista de que as organizações possuem uma cultura própria, na qual as mantém ativas. Com base nisto, o estudo buscou responder o seguinte questionamento: Os valores, os princípios, a qualidade e as normas defendidas pelas instituições de ensino superior são condizentes com as expectativas dos discentes? Como objetivo geral, buscou-se identificar através do instrumento de coleta de dados, o posicionamento e a visão dos alunos frente a sua instituição de ensino, e com isto, averiguar de forma prática no que interfere os fatores institucionais frente a este segmento no mercado, entretanto, segundo a percepção dos alunos. O estudo foi aplicado com 216 alunos do curso de Administração, do quinto, sexto e sétimo semestre, em duas universidades privadas.

Por fim, a estrutura percorrida para o desenvolvimento do trabalho encontra-se dividido em cinco partes. Além desta introdução, apresenta-se o aporte teórico que versa sobre a teoria institucional, isomorfismo e a dinâmica e cultura organizacional. Em seguida, o método busca abordar as definições e descrições referentes aos procedimentos metodológicos adotados. Após, discute-se os resultados por meio da análise de média simples das variáveis utilizadas 
para o estudo das temáticas. Por fim, demostra-se nas considerações finais, o grau de importância do tema com relação ao ambiente institucional de universidade privadas.

\section{Teoria Institucional e o Isomorfismo}

A teoria institucional refere-se a padrões estáveis e de comportamento, que determinadas organizações assumem como necessidade social e eficaz, tornando-se parte do repertório e do cotidiano das organizações (TOLBERT, ZUCKER, 2010). Deste modo, a institucionalização do ensino superior também nos remete as questões que envolvem valores, crenças, e normas advindas dos princípios cultuados pelas organizações (TOLBERT; ZUCKER, 2010).

É possível inferir que a teoria institucional encontra-se diretamente ligada aos fatores sociais: abarcando crenças, ideologias, valores e culturas disseminadas cotidianamente pelas organizações. Deste modo, toda organização é dotada de uma cultura própria, difundida pelas pessoas que pertencem ao grupo.

Por outro lado, a teoria institucional descrita por meio da "nova escola institucional", examina as diferentes relações entre o meio e o equilíbrio organizacional, como ação benéfica a determinados segmentos e áreas de mercado, buscando com isso um processo de manutenção das relações de grupos sociais mais duradouros (TOLBERT; ZUCKER, 2010).

Assim, o processo de institucionalização é descrito como contínuo visando o desenvolvimento e a perpetuação das relações que envolvem grupos organizacionais, desenvolvendo e construindo uma identidade organizacional. Ou seja, a teoria institucional busca explicar as perspectivas e as estruturas organizacionais envolvidas frente a construção da identidade empresarial.

Neste sentido, a teoria institucional parte do pressuposto de que as organizações possuem valores sociais e de tal modo que dissipam e influenciam diretamente o meio em que atuam. Porém, também podemos observar conceitos adversos a institucionalização, correspondendo a um "caminho contrário", caracterizado pela reconstrução, desestruturação e até a descontinuidade do negócio. Tal processo é denominado como "desinstitucionalização". A desinstitucionalização surge como tendência a descontinuidade, promovido em razão do desgaste do negócio. “Os mecanismos que dão início a esse processo podem ser de ordem social e histórica, destacando-se as sucessões, as fusões e as aquisições” (RIBEIRO, 2011, p.9). 
A teoria institucional surgiu como uma medida de tentar explicar a relação de diversidade existente entre as organizações, seja por questões "materiais, sobre os princípios, e o comportamento dos indivíduos, assim, buscando compreender a homogeneidade de formas e práticas institucionais (DIMAGGIO; POWELL, 2005, p.5).

Deste modo, após compreender a teoria que envolve as organizações e o seu processo de difusão frente a cultura organizacional, adaptada ao modelo mercadológico, é que se torna possível vislumbrar o conceito de Isomorfismo. Neste sentido, o isomorfismo pressupõe que as instituições reagem de maneira similar ou igual as demais organizações, enquanto buscam adequar-se ao ambiente (HANNAN, FREEMAN, 2005).

Segundo Machado-da-Silva e Fonseca (1993), a busca pelo isomorfismo ocorre quando problemas dificilmente de serem sanados são identificados, e com isto, as instituições são forçadas a introduzir atitudes inovadoras e próprias dentro do negócio. Assim, as demais empresas atuantes no mesmo ramo de negócio são obrigadas a tomarem como mecanismos de autodefesa atitudes que permeiam uma postura isomórfica, ou seja, utilizam-se das mesmas estratégias de negócios atribuídas pelas empresas líderes do segmento, ou então assumem processos semelhantes, adaptando-se ao mercado por meio de regras socialmente aceitas pelo contexto geral (FERREIRA, FILHO E BELTRÃO, 2013).

Tanto na teoria institucional, a qual se refere a ambientes altamente controlados, buscando alcançar a conformidade e isonomia interna como externa (FERREIRA, FILHO E BELTRÃO, 2013), o isomorfismo, é uma ferramenta utilizada para buscar o controle organizacional frente as adversidades do mercado, adotando atitudes homogêneas do segmento, tratando-se de uma medida defensiva e de sobrevivência.

\subsection{Dinâmica Organizacional e as Universidades de Ensino Superior Privado}

Quando nos referimos a dinâmica organizacional, podemos refletir que uma Instituição de Ensino Superior privado também sofre dos mesmos anseios e ameaças que uma organização atuante sobre qualquer setor ou ramo de atuação, sofre. Ou seja, uma instituição privada é diretamente voltada ao lucro, entretanto, preocupa-se com aspectos mercadológicos do tipo: concorrência, gastos, despesas de produção, legislação e adaptação aos aspectos governamentais entre outros aspectos de relevância que emerge qualquer organização.

Assim, frente a um mercado cada vez mais competitivo e em constante crescimento, surge a necessidade de as universidades privadas buscarem aprimorar seus métodos de ensino, bem como, se adequarem as exigências voltadas aos seus clientes e ao mercado, como um 
todo. Entretanto "é importante salientar que uma universidade não deve limitar-se apenas ao aspecto político pedagógico, deixando de lado a gestão dos meios a serem utilizados para que seus fins sejam alcançados” (FERREIRA, FILHO E BELTRÃO, 2013, p.4). Ou seja, “as universidades não dispõem apenas de pessoas que desempenham atividades de ensinoaprendizagem, mas também de indivíduos que realizam atividades que estão ligadas à direção, e ao processo pedagógico" (FERREIRA, FILHO E BELTRÃO, 2013, p.4).

Assim,

Adotando um modelo de gestão que seja eficiente, a universidade conseguirá assumir uma postura ágil na administração de suas informações, além de cumprir a sua missão, que se trata de oferecer um serviço de ensino de alta qualidade, quando se fala em universidade privada, essas instituições precisam obter dos seus processos rotineiros resultados positivos, e seus administradores têm por obrigação apresentar uma gestão eficaz que consiga atingir um equilíbrio entre o oferecimento de um ensino de qualidade e os resultados positivos entre os negócios empresariais (BEZERRA, 2010, p.10).

Ainda, devido à elevada procura por qualificação profissional, como também, devido a intensa competição das organizações neste segmento, é que muitas instituições vêm aprimorando-se e exigindo novos padrões de conduta e postura, tanto por parte dos docentes, bem como, por meio dos gestores, como ocorre, similarmente a qualquer instituição tradicional, que visa o lucro. Assim, "a maioria das instituições se preocupa em não ficar na contramão das exigências de produtividade, competência e qualidade, contudo a educação deve ser compreendida sim, numa perspectiva de mercado, e o aluno como cliente conforme sua posição de consumidor de serviços (educação)" (VASCONCELOS, 2002, p.9).

\footnotetext{
Atualmente as instituições de ensino superior privadas atuam como verdadeiras organizações. Assim como o ambiente em que se vive hoje, elas precisam seguir a lógica do funcionamento de uma organização empresarial, inseridas em um campo altamente competitivo, onde o "produto", que corresponde a formação, será como um objeto de consumo. E para mostrar seu "produto" de uma forma que seja capaz de atender as expectativas alheias, as universidades precisam rever a forma de como estão sendo gerenciadas, pois necessitam de um modelo que venha de uma estrutura organizacional (SGUISSARDI, 2004, p.4).
}

A questão é que como o ensino superior privado vêm expandindo-se de forma crescente e acelerada, torna-se inevitável a preocupação mercadológica quanto a continuidade do negócio. Desta maneira, tais instituições não somente estão preocupadas com fatores legais, físicas, materiais, ou com a qualidade. Atualmente é possível perceber que em sua maioria, as organizações estão voltando seu olhar sobre questões que envolvem valores e princípios, bem como, a forma com que são visualizadas no mercado, buscando continuamente transparecer uma visão positiva frente a sociedade (BRESSAN, 2004). 


\subsection{Mercantilização e o Ensino Superior Privado}

Frente a expansão do ensino superior, pode-se perceber diversas mudanças socioeconômicas e político-culturais nas últimas décadas, onde visivelmente pode-se acompanhar um elevado crescimento avindo da expansão das instituições de ensino superior, como sugere o quadro 01 (MINTO, 2011).

Quadro 1- Número de IES - Brasil

\begin{tabular}{|c|c|c|c|c|c|}
\hline Período & Total & Federal & Estadual & Municipal & Privada \\
\hline 2001 & 1391 & 67 & 53 & 53 & 1208 \\
\hline 2002 & 1637 & 73 & 57 & 57 & 1442 \\
\hline 2003 & 1859 & 83 & 59 & 59 & 1652 \\
\hline 2004 & 2013 & 87 & 62 & 62 & 1789 \\
\hline 2005 & 2165 & 97 & 59 & 59 & 1934 \\
\hline 2006 & 2270 & 105 & 60 & 60 & 2022 \\
\hline 2007 & 2281 & 106 & 61 & 61 & 2032 \\
\hline 2008 & 2252 & 93 & 61 & 61 & 2016 \\
\hline 2009 & 2314 & 94 & $\mathbf{8 4}$ & 67 & 2069 \\
\hline 2010 & 2387 & 99 & 108 & 71 & 2100 \\
\hline
\end{tabular}

Fonte: Brasil. INEP.

Assim, conforme Queiroz, Queiroz e Hékis (2011, p.5) quando nos referimos ao ensino superior, "observa-se uma demanda crescente por vagas, por meio da concorrência e da abertura de novas instituições, tanto na modalidade de cursos presenciais, semi-presenciais e a distância”. É por meio destes conceitos que atualmente, não se torna equivocado tentar comparar Instituições de Ensino Superior privadas com a funcionalidade e finalidade de uma organização.

Desta forma, o princípio que norteia a funcionalidade de uma empresa se reflete na prestação de bens e de serviços, que venham proporcionar a lucratividade e o crescimento financeiro da organização. Assim, ao que tange as universidades privadas, o seu faturamento se encontra "atrelado principalmente à cobrança de taxas de matrículas e de mensalidades dos alunos matriculados", em consequência da prestação de serviços educacionais que visam formar e qualificar seu público para o mercado de trabalho (QUEIROZ, QUEIROZ E HÉKIS, 2011, p.5).

Devido a expansão do ensino superior no cenário brasileiro, e tendo em vista a competitividade neste segmento, atualmente, muitas organizações educacionais têm ampliado seu foco por meio da busca de padrões de eficiência a sua gestão (Scharmach, 2009). Assim, é possível inferir que a ampliação e a busca crescente de qualificação fazem com que a indústria ou o oligopólio do ensino venha sofrer um grande desenvolvimento e ampliação do negócio 
sobre a ótica do mercado, onde o principal produto/serviço ofertado é a promoção do ensino, enquanto o aluno é caracterizado como "cliente" da instituição em que se encontra matriculado.

Por outro lado, é possível vislumbrar que o aluno na qualidade de "consumidor" é capaz de discernir suas escolhas frente as suas preferências pessoais, ou seja, a escolha da instituição em que pretende usufruir do ensino, buscando adequar valores da instituição frente as suas preferências individuais.

Desta forma, segundo ABMES (s/d., p. 9) aponta que a "presença do capital privado no ensino superior, além de movimentar algo em torno de 32 bilhões de reais por ano, onde, não é casual que essa fração da burguesia - a "burguesia de serviços" - esteja cada vez mais fortalecida e prepotente". E neste sentido, é que existe a grande preocupação com a fidelização do aluno junto a instituição aliada e a busca de novos "clientes.

Assim, mesmo que o ensino atualmente configure um grande mercado em expansão, é de grande preocupação por parte das instituições a busca pela satisfação do seu público, onde, além de ofertar um ensino de qualidade, procura aliar ao negócio outros atributos como a qualidade, competência da gestão, e demais questões até mesmo atribuídas aos valores promovidos pela instituição.

\section{3- MÉTODO}

Por meio deste estudo, e como objetivo geral, procura-se identificar a percepção e a visão dos alunos frente a instituição de ensino, analisando de forma prática como os fatores institucionais podem afetar/ou não, a percepção dos discentes frente ao ensino superior privado, no que tange ao curso bacharelado em administração. Este artigo parte inicialmente da curiosidade em discernir os fatores de envolvimento e a influência que os discentes buscam, frente as instituições de ensino privado, quanto a fatores institucionais como princípios, qualidade, normas/padrões de conduta, cultura e comportamentos que estas empresas priorizam e que instigam os discentes a permanecerem em tais instituições.

A pesquisa possui caráter quantitativo- exploratório em razão da necessidade de buscar uma fundamentação teórica clássica e atualizada quando nos referimos as temáticas: institucionalização do ensino, isomorfismo e a cultura e dinâmica organizacional. Logo, de forma prática, buscou-se contemplar a visão dos alunos do curso de administração de universidades privadas, a parir do quinto semestre dos municípios de Cerro Largo e Santo Ângelo. Também, procurou-se por meio desta região aplicar um questionário estruturado com 
questões fechadas, já validado, por meio do modelo de Siqueira e Tamayo (2008), quanto a uma análise do envolvimento dos indivíduos quanto a cultura organizacional.

$\mathrm{Na}$ fase da coleta de dados e informações para o estudo, fez-se necessário adaptar algumas questões, porém, o modelo de questionário de Siqueira e Tamayo (2008). Foram aplicados 216 questionários aos acadêmicos do ensino superior. O modelo aplicado utilizouse de uma escalas de 1 a 5, tendo em vista medir e discriminar o comportamento e a influência dos princípios organizacionais por meio dos alunos de instituições de ensino privado.

Também, tendo em vista o modelo de de Siqueira e Tamayo(2008), o mesmo apresenta-se subdividido em três categorias, sendo elas: perfil dos estudantes; importância da instituição, e por fim, relação da instituição quanto as pretensões dos discentes com o curso.

\section{ANÁLISE DOS RESULTADOS}

Para a concretização do estudo, foi aplicado um modelo de questionário validado por Siqueira e Tamayo (2008), seguido por adaptações. Desta maneira, procurou-se então abranger a população concluinte ou, aqueles alunos que se encaminham em fase de conclusão do curso, para então analisar se de alguma maneira houve influência da instituição sobre as suas escolhas, e análise das atitudes promulgadas pelos mesmo. O estudo então foi aplicado em duas universidades particulares no Estado do Rio Grande do Sul, mencionadas como Universidade Alfa e Universidade Beta, buscando-se então não expor a real identidade as instituições ensino, atribuindo-se nome "fantasia" as mesmas. Assim, dos respondentes da pesquisa, 35\% dos alunos pertenciam a universidade Alfa, e $65 \%$ dos acadêmicos pertenciam a instituição Beta (quadro 02).

Após a fase da coleta dos dados, realizou-se então a análise e a discriminação das informações referente ao perfil dos estudantes acadêmicos em Administração (alunos do quinto, ao sétimo semestre) de duas universidades privadas. Assim, considera-se que participaram da pesquisa 216 acadêmicos.

Do total da população, $45 \%$ dos respondentes pertencem ao gênero masculino, enquanto que 55\% constituem indivíduos do gênero feminino. Com tais informações, é possível presumir que as mulheres encontram-se cada vez mais preocupadas com a qualificação profissional, bem como, buscando espaço frente ao mercado de trabalho, visto que em décadas passadas, correspondia a uma minoria sem expressão dentro da sociedade (quadro 02). 
Quadro 2 - Caracterização dos Respondentes

\begin{tabular}{|c|c|c|c|c|c|c|c|}
\hline & \multicolumn{3}{|c|}{ Alfa } & \multicolumn{4}{|c|}{ Beta } \\
\hline Universidade & \multicolumn{3}{|l|}{76 alunos } & \multicolumn{4}{|l|}{140 alunos } \\
\hline & \multicolumn{3}{|c|}{ Feminino } & \multicolumn{4}{|c|}{ Masculino } \\
\hline \multirow{2}{*}{ Gênero } & \multicolumn{3}{|l|}{97 alunos } & \multicolumn{4}{|l|}{119 alunos } \\
\hline & $\begin{array}{l}\text { Até } 24 \\
\text { anos }\end{array}$ & $\begin{array}{c}25 \text { a } 34 \\
\text { anos }\end{array}$ & $\begin{array}{c}35 \text { a } \\
\text { 44anos }\end{array}$ & \multicolumn{2}{|c|}{45 a 54anos } & \multicolumn{2}{|c|}{ Mais de 55 anos } \\
\hline \multirow[t]{2}{*}{ Faixa Etária } & 162 alunos & 43 alunos & 7 alunos & \multicolumn{2}{|l|}{4 alunos } & \multicolumn{2}{|c|}{0 alunos } \\
\hline & $\begin{array}{l}\text { Inf. Ou Igual } \\
\text { a } 765,00 \text { reais }\end{array}$ & $\begin{array}{c}\text { De } 765,00 \text { a } \\
1530,00 \text { reais }\end{array}$ & $\begin{array}{l}\text { De } 1530,00 \text { a } \\
2295,00 \text { reais }\end{array}$ & $\begin{array}{l}\text { De } 2295,00 \text { a } \\
3060,00 \text { reais }\end{array}$ & & $\begin{array}{l}0,00 \mathrm{a} \\
\text { reais }\end{array}$ & $\begin{array}{c}\text { Mais de } \\
5000,00 \\
\text { reis }\end{array}$ \\
\hline $\begin{array}{l}\text { Renda } \\
\text { Familiar }\end{array}$ & 32 alunos & 84 alunos & 32 alunos & 22 alunos & & & 24 alunos \\
\hline
\end{tabular}

Fonte: Dados da pesquisa.

Quanto a faixa etária dos respondentes, o estudo revelou que a maioria dos acadêmicos de administração do quinto ao sétimo semestre possuem idade inferior a 24 anos, ou seja, $75 \%$ dos respondentes (quadro 02 ). Outra informação relevante a considerar, é que $20 \%$ dos respondentes da pesquisa possuem idade entre 25 a 34 anos. Podendo-se inferir que a população acadêmica provavelmente buscou a qualificação superior logo que concluiu o ensino médio (quadro 02).

Por meio do quadro 02, é possível destacar que a renda familiar dos respondentes da pesquisa é inferior ou igual a 765,00 reais. Por outro lado, 39\% dos alunos apontaram que sua renda familiar varia de 765,00 reais a 1530,00 reais, caracterizando-se como famílias pertencentes a classe média. Também, $15 \%$ dos participantes ressalta que sua renda familiar é de 1530,00 reais a 2295,00 . Com tais informações, é possível descrever que a maioria dos respondentes pertencem a classe média e a classe média baixa, em função do curso não exigir grandes gastos com recursos materiais ou de grandes investimentos financeiros.

Outra informação relevante obtida por meio da pesquisa, foi que $71 \%$ dos alunos procuram conciliar alguma atividade lucrativa para poder dar continuidade aos estudos e para sua própria sobrevivência, contra $29 \%$ dos alunos que somente estudam. 
Gráfico 1 - Renda Familiar dos respondentes

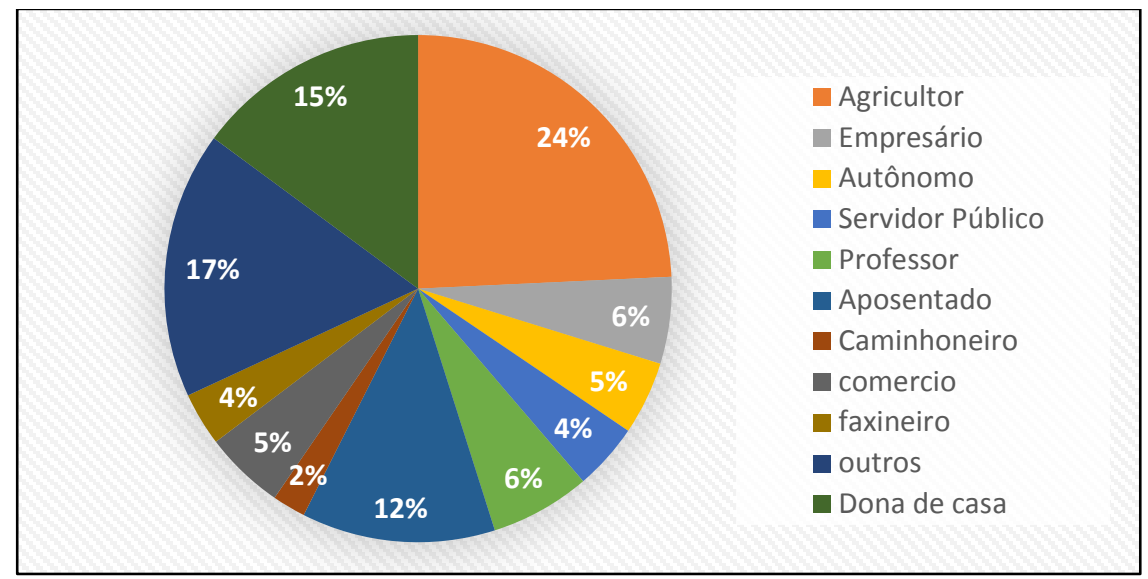

Fonte: Dados da pesquisa

O gráfico 01 busca demonstrar a atividade profissional familiar. Neste sentido, é possível corroborar que a escolha profissional, não partiu de influência familiar de primeiro grau. Em muitos casos, a escolha do curso de administração ocorre por ser acessível financeiramente, e abrange a atuação em diversas áreas. Conforme o gráfico 01, a maioria dos respondentes, afirmam que têm familiares de primeiro grau agricultores, aposentados, servidores públicos entre outros.

\subsection{Análise dos Valores Organizacionais}

Tendo em vista os objetivos pelo qual houve a motivação de realizar o estudo, buscouse então, analisar como os discentes enxergam a instituição superior onde buscam a qualificação, e o grau de relevância auferida pelo acadêmico. Buscou-se então, analisar questões envolvendo satisfação, mudança de valores e motivação, por meio de 07 variáveis que compõem o questionário, como demonstra o quadro 03.

Quadro3 - Importância da Instituição

\begin{tabular}{|l|c|c|c|c|c|}
\hline \multicolumn{1}{|c|}{ IMPORTÂNCIA DA INSTITUIÇ̃̃o } & $\begin{array}{l}\text { Discordo } \\
\text { Totalmente }\end{array}$ & Discordo & Indiferente & Concordo & $\begin{array}{l}\text { Concordo } \\
\text { Totalmente }\end{array}$ \\
\hline $\begin{array}{l}\text { 1 Desde que entrei nesta instituição, } \\
\text { meus valores pessoais têm se tornado } \\
\text { mais similares }\end{array}$ & $3,05 \%$ & $4,58 \%$ & $29,01 \%$ & $49,62 \%$ & $9,92 \%$ \\
\hline $\begin{array}{l}\text { 2 Eu prefiro esta organização em relação } \\
\text { a outras por causa do que ela simboliza e } \\
\text { seus valores }\end{array}$ & $4,58 \%$ & $11,45 \%$ & $28,24 \%$ & $42,75 \%$ & $12,21 \%$ \\
\hline $\begin{array}{l}\text { 3 Eu me identifico com a filosofia desta } \\
\text { instituição }\end{array}$ & $3,05 \%$ & $8,40 \%$ & $40,46 \%$ & $36,64 \%$ & $12,21 \%$ \\
\hline $\begin{array}{l}\text { 4 Eu acredito nos valores e objetivos } \\
\text { desta instituição }\end{array}$ & $2,29 \%$ & $4,58 \%$ & $23,66 \%$ & $49,62 \%$ & $16,79 \%$ \\
\hline 5 Não deixaria minha instituição agora & $16,79 \%$ & $12,21 \%$ & $31,30 \%$ & $24,43 \%$ & $13,74 \%$ \\
\hline
\end{tabular}




\begin{tabular}{|l|c|c|c|c|c|}
\hline $\begin{array}{l}\text { porque tenho obrigação moral com as } \\
\text { pessoas daqui }\end{array}$ & & & & \\
\hline $\begin{array}{l}\text { 6 Mesmo se fosse vantagem para mim, } \\
\text { sinto que não seria certo deixar minha } \\
\text { instituição agora }\end{array}$ & $22,90 \%$ & $14,50 \%$ & $25,19 \%$ & $22,14 \%$ & $12,21 \%$ \\
\hline $\begin{array}{l}\text { 7 Eu me sentiria culpado se deixasse } \\
\text { minha universidade }\end{array}$ & $26,72 \%$ & $28,24 \%$ & $19,85 \%$ & $16,79 \%$ & $6,87 \%$ \\
\hline
\end{tabular}

Fonte: Dados da Pesquisa

Abaixo segue análise realizada conforme os resultados transmitidos pelo Quadro 02.

\subsubsection{Similaridade de Valores Pessoais com a Instituição De Ensino}

Tendo em vista a variável "1-Desde que entrei nesta instituição, meus valores pessoais têm se tornado mais similares", foi possível perceber que 49,62\% dos respondentes revelaram que concordam. Em continuidade, $42,75 \%$ dos respondentes concordaram com a variável "Eu prefiro esta organização em razão dos seus valores". Ou seja, é possível destacar que a escolha da universidade, para a maioria dos estudantes se encontra diretamente ligada aos valores e princípios carregados pela instituição, dissipados entre o meio acadêmico (quadro 03), principalmente por se tratar de universidades particulares, onde a escolha do curso e da universidade está atrelado a diversos fatores, como econômicos, estruturais, qualidade, princípios pregados pela instituição, conduta ética/transparente entre outros.

Quanto a variável "Eu me identifico com a filosofia desta instituição", 40,46\% dos respondentes apontaram ter valor indiferente. Ou seja, busca-se uma boa instituição que aplique em seu cotidiano bons princípios e ideologias, mesmo que, como indivíduo e aluno tais fatores não sejam cultuados de maneira direta. A variável "Eu acredito nos valores e objetivos desta instituição apresentou 49,62\% de aceitação, onde os indivíduos concordam com esta colocação (quadro 03).

Em outras palavras, a conduta dos indivíduos tornou-se mais similar aos padrões pregados pelas universidades privadas, logo após ingressarem na instituição de ensino superior. Entretanto, não configuram um fator primordial para a continuidade e fidelização do indivíduo sobre a mesma universidade, onde, se, o aluno necessitar migrar de uma universidade para a outra, por algum motivo em específico, o mesmo não enxergará barreiras para realizar tal mudança.

\subsubsection{Valor Moral e a Permanência Institucional}

A variável "5-Não deixaria minha instituição agora porque tenho obrigação moral com as pessoas daqui" possibilitou demonstrar que os alunos são indiferentes a este posicionamento; bem como, indiferentes, ao posicionamento demonstrado pela variável "6- 
Mesmo se fosse vantagem para mim, sinto que não seria certo deixar minha instituição agora”. Já a variável 7- "Eu me sentiria culpado se deixasse minha universidade" apresenta uma informação relevante, onde $28,24 \%$ dos respondentes discordam de tal proposição.

De tal modo, na primeira seção destacada como "Similaridade de Valores Pessoais com a Instituição De Ensino" sobre a Importância da Instituição, conclui-se que a escolha da universidade está diretamente ligada a sua cultura organizacional interna, e suas ideologias cultivadas e propagadas em seu meio. Entretanto, não é um fator de grande relevância que venha assegurar que o aluno não acabe migrando para outra instituição em que julgar mais vantajosa, quando refere-se a continuidade e permanência.

Dando seguimento ao estudo, o quadro 04 esclarece como é desenvolvida a relação dos alunos com a própria instituição, ressaltando o desempenho e o comportamento do discente segundo a sua motivação de pertencimento a determinada instituição e ao grupo. Segundo o quadro 04, é possível visualizar 21 variáveis que procuram demonstrar tal relação.

Quadro 4 - Papel como Aluno e Relações com a Instituição

\begin{tabular}{|c|c|c|c|c|c|}
\hline $\begin{array}{l}\text { QUANTO AO PAPEL COMO ALUNO } \\
\text { E RELACÕES COM A INSTITUICÃO }\end{array}$ & $\begin{array}{l}\text { Disc. } \\
\text { Totalmente }\end{array}$ & Discordo & Indiferente & Concordo & Totalmente \\
\hline $\begin{array}{l}1 \text { Todo aluno deve buscar atingir os } \\
\text { objetivos da universidade }\end{array}$ & $6,87 \%$ & $3,82 \%$ & $13,74 \%$ & $41,22 \%$ & $32,82 \%$ \\
\hline $\begin{array}{l}2 \text { Eu tenho obrigação em desempenhar } \\
\text { bem minha função como aluno }\end{array}$ & $1,53 \%$ & $2,29 \%$ & $5,34 \%$ & $46,56 \%$ & $43,51 \%$ \\
\hline $\begin{array}{l}3 \text { O aluno deve se esforçar para que a } \\
\text { instituição possua os melhores resultados } \\
\text { possíveis }\end{array}$ & $2,29 \%$ & $4,58 \%$ & $12,98 \%$ & $44,27 \%$ & $35,88 \%$ \\
\hline $\begin{array}{l}40 \text { aluno têm a obrigação de sempre } \\
\text { cumprir suas tarefas }\end{array}$ & $2,29 \%$ & $5,34 \%$ & $12,21 \%$ & $45,80 \%$ & $32,82 \%$ \\
\hline $\begin{array}{l}5 \text { Nesta universidade, eu sinto que faço } \\
\text { parte de um grupo }\end{array}$ & $5,34 \%$ & $5,34 \%$ & $20,61 \%$ & $41,22 \%$ & $25,95 \%$ \\
\hline $\begin{array}{l}6 \text { Sinto que meus colegas me consideram } \\
\text { como membro do grupo }\end{array}$ & $7,63 \%$ & $6,87 \%$ & $17,56 \%$ & $41,22 \%$ & $23,66 \%$ \\
\hline $\begin{array}{l}7 \text { Se eu já não tivesse dado tanto de mim } \\
\text { neste curso, eu poderia migrar para outra } \\
\text { instituição }\end{array}$ & $14,50 \%$ & $19,08 \%$ & $28,24 \%$ & $20,61 \%$ & $16,03 \%$ \\
\hline $\begin{array}{l}8 \text { A menos que eu seja recompensado de } \\
\text { alguma maneira, eu não vejo razões para } \\
\text { despender esforços extra em benefícios } \\
\text { desta instituição }\end{array}$ & $18,32 \%$ & $14,50 \%$ & $34,35 \%$ & $19,08 \%$ & $9,16 \%$ \\
\hline $\begin{array}{l}9 \text { Minha visão pessoal sobre esta } \\
\text { instituição é diferente daquela que eu } \\
\text { expresso publicamente }\end{array}$ & $27,48 \%$ & $24,43 \%$ & 27,48 & $13,74 \%$ & $6,11 \%$ \\
\hline $\begin{array}{l}10 \text { Apesar dos esforços que já realizei, } \\
\text { não vejo oportunidades para mim nesta } \\
\text { instituição }\end{array}$ & $24,43 \%$ & $30,53 \%$ & $23,66 \%$ & $12,21 \%$ & $6,87 \%$ \\
\hline $\begin{array}{l}11 \text { Procuro não transgredir regras; pois } \\
\text { assim sempre manterei uma boa imagem } \\
\text { dentro do curso }\end{array}$ & $6,11 \%$ & $8,40 \%$ & $24,43 \%$ & $35,11 \%$ & $21,37 \%$ \\
\hline $\begin{array}{l}12 \text { Na situação atual, ficar com minha } \\
\text { universidade/curso é na realidade uma } \\
\text { necessidade tanto quanto um desejo }\end{array}$ & $6,11 \%$ & $9,92 \%$ & $26,72 \%$ & $38,17 \%$ & $16,03 \%$ \\
\hline $\begin{array}{l}13 \text { Para conseguir ser recompensado aqui } \\
\text { é necessário expressar a atitude certa }\end{array}$ & $6,11 \%$ & $4,58 \%$ & $26,72 \%$ & $42,75 \%$ & $15,27 \%$ \\
\hline $\begin{array}{l}14 \text { Seu eu decidisse abandonar agora meu } \\
\text { curso, minha vida ficaria bastante } \\
\text { desestruturada }\end{array}$ & $9,16 \%$ & $13,74 \%$ & $17,56 \%$ & $33,59 \%$ & $22,90 \%$ \\
\hline
\end{tabular}




\begin{tabular}{|l|c|c|c|c|c|}
\hline $\begin{array}{l}\text { 15 Dou máxima atenção aos professores, } \\
\text { escutando executando tudo o que é } \\
\text { mencionado }\end{array}$ & $1,53 \%$ & $6,87 \%$ & $18,32 \%$ & $47,33 \%$ & $18,32 \%$ \\
\hline $\begin{array}{l}\text { 16 Consigo facilmente influenciar pessoas } \\
\text { com meus pontos de vista e minhas } \\
\text { opiniões }\end{array}$ & $3,82 \%$ & $10,69 \%$ & $28,24 \%$ & $39,69 \%$ & $12,98 \%$ \\
\hline $\begin{array}{l}\text { 17 Visualizo a universidade como local de } \\
\text { contato pessoal, pertencimento a um } \\
\text { determinado grupo e rede de } \\
\text { relacionamentos }\end{array}$ & $5,34 \%$ & $5,34 \%$ & $23,66 \%$ & $44,27 \%$ & $22,14 \%$ \\
\hline $\begin{array}{l}\text { 18 Minha universidade possui uma ótima } \\
\text { qualidade de ensino }\end{array}$ & $5,34 \%$ & $7,63 \%$ & $14,50 \%$ & $45,80 \%$ & $24,43 \%$ \\
\hline $\begin{array}{l}\text { 19 Me mantenho na maior parte do } \\
\text { tempo ocupado com trabalhos do curso }\end{array}$ & $5,34 \%$ & $14,50 \%$ & $30,53 \%$ & $35,88 \%$ & $12,21 \%$ \\
\hline $\begin{array}{l}\text { 20 Me encontro sempre disposto a } \\
\text { aprender }\end{array}$ & $13,74 \%$ & $3,05 \%$ & $16,03 \%$ & $29,01 \%$ & $24,43 \%$ \\
\hline $\begin{array}{l}\text { 21 Todo semestre pego ao menos um } \\
\text { exame }\end{array}$ & $26,72 \%$ & $18,32 \%$ & $14,50 \%$ & $24,43 \%$ & $12,21 \%$ \\
\hline
\end{tabular}

Fonte: Dados da Pesquisa Quadro 04.

Em continuidade, segue análise realizada conforme os resultados apontados pelo

\subsubsection{Objetivos Educacionais e a Instituição}

Assim, por meio da variável "1- Todo aluno deve buscar atingir os objetivos da universidade", 41,22\% dos discentes concordam com esta colocação. A variável 2 corrobora que "Eu tenho obrigação em desempenhar bem minha função como aluno", 46,56\% dos acadêmicos também concordam com esta afirmação. E na variável "3- O aluno deve se esforçar para que a instituição possua os melhores resultados possíveis", 44,27\% dos alunos concordam com esta variável.

Então, pode-se destacar que grande parte dos discentes possuem o sentimento de obrigação com a instituição, procurando desempenhar um bom papel como aluno, e como consequência, atingir os objetivos da instituição (Quadro 04). Ou seja, busca-se um relação recíproca de troca, tanto entre aluno e instituição e vice versa. $\mathrm{O}$ aluno busca um ensino de qualidade que venha a lhe agregar conhecimentos específicos para sua vida profissional, já em contrapartida, a instituição espera do aluno a maximização do conhecimento oferecido pela instituição, revertendo em uma visão de qualidade para o seu público alvo, considerando-se que as empresas privadas, em grande maioria, precisam ser enxergadas de forma positiva, refletindo basicamente como um diferencial competitivo, e também, como um fator de grande influência quando nos referimos a sobrevivência deste tipo de negócio. 


\subsubsection{Sentimento de Inclusão}

Concordam 41,22\% dos respondentes com a afirmativa "5- Nesta universidade, eu sinto que faço parte de um grupo. Em continuidade, 41,22\% dos acadêmicos também concordam com a variável "6- Sinto que meus colegas me consideram como membro do grupo". Ou seja, é possível perceber que o sentimento aceitação pelos colegas bem como de pertencimento a um determinado grupo, ou seja, os discentes admitem possuir influência direta quanto a escolha, continuidade e pertencimento a instituição (quadro 4).

\subsubsection{Instituições e seus Benefícios}

A variável "7- Se eu já não tivesse dado tanto de mim neste curso, eu poderia migrar para outra instituição", 28,24\% dos respondentes se mostram indiferentes com esta afirmativa. Também, a variável "8- A menos que eu seja recompensado de alguma maneira, eu não vejo razões para despender esforços extras em benefício desta instituição", 34,35\% dos respondentes se mostraram indiferentes. Ou seja, o fator "desempenho" não constitui e não condiciona uma questão motivacional para a continuidade ou desistência do curso e da instituição em que o indivíduo está matriculado (quadro 04).

Seguindo o que nos apresenta o quadro $04,27,48 \%$ dos discentes apontam ser indiferentes, e discordam totalmente que "9-Minha visão pessoal sobre esta instituição é diferente daquela que eu expresso publicamente", ou seja, os alunos buscam posicionar-se quanto as suas visões e pontos de vista a respeito da universidade em que se encontram inseridas.

Por outro lado, os discentes não buscam beneficiar-se com a instituição de outra maneira que não seja a prestação dos serviços por ela desempenhados. Ou seja, os alunos não buscam benefícios diferentes dos serviços oferecidos, no caso, o ensino.

\subsubsection{Importância e sentimento de Apego a Instituição}

Conforme os dados analisados para o atual estudo, é possível perceber um sentimento de apego quanto aos esforços despendidos pelos alunos, ao observar o que a variável 10 apresenta: “Apesar dos esforços que já realizei, não vejo oportunidades para mim nesta instituição", onde 30,53\% dos alunos discordam dessa afirmação.

Quanto a variável "11- Procuro não transgredir regras; pois assim sempre manterei uma boa imagem dentro do curso" 35,11\% dos discentes concordam com esta afirmação. Já a 
variável "12- Na situação atual, ficar com minha universidade/curso é na realidade uma necessidade tanto quanto um desejo", $37,17 \%$ dos respondentes também concordam com esta colocação. Deste modo, é possível traçar uma linearidade entre as respostas quanto a necessidade de procurar não transgredir regras morais da instituição para dar continuidade ao curso, pois configura uma questão de necessidade de qualificação profissional, bem como, demostrar uma imagem disciplinar positiva (quadro 04).

A afirmativa" 14-Seu eu decidisse abandonar agora meu curso, minha vida ficaria bastante desestruturada" apresentou 33,59\%de aceitação por parte dos estudantes. Acredita-se que pelo tempo despendido durante o curso de longa duração, pelos recursos financeiros aplicados, bem como pela necessidade de qualificação profissional, o abandono do curso seria analisado de maneira negativa pelo discente, pela grande importância inferida pelo aluno.

\subsubsection{Influência do curso sobre os discentes}

Em seguida, 39,69\% dos respondentes concordaram que "16-Consiguem facilmente influenciar pessoas com pontos de vista e opiniões. Assim, esta variável pode ser condicionada ao fato do curso de administração formar "tomadores" de decisões/gestores capazes de influenciar de maneira crítica e aplicável ao cotidiano atitudes positivas frente ao mercado.

Por fim, há uma grande relação entre as seguintes variáveis: "19- Me mantenho na maior parte do tempo ocupado com trabalhos do curso"; "20- Me encontro sempre disposto a aprender", onde grande parcela dos respondentes concordam com tais proposições, pois infere-se que os discentes buscam priorizar a qualidade e o aprendizado pessoal quanto ao ensino ofertado. Também, 26,72\% dos discentes discordam totalmente com a variável "21 Todo semestre pego ao menos um exame", pois mesmo se tratando de uma universidade privada, os alunos procuram valorizar sua instituição e inferir maior qualidade frente ao seu nível de aprendizado (quadro 04).

Quadro 5 - Quanto as Pretensões com a conclusão do curso

\begin{tabular}{|l|c|c|c|c|c|}
\hline \multicolumn{1}{|c|}{$\begin{array}{c}\text { Quanto as Pretensões com a } \\
\text { conclusão do curso }\end{array}$} & $\begin{array}{c}\text { Disc. } \\
\text { Totalmente }\end{array}$ & Discordo & Indiferente & Concordo & $\begin{array}{c}\text { Conc. } \\
\text { Totalmente }\end{array}$ \\
\hline $\begin{array}{l}\text { 1 Quero abrir um negócio após o } \\
\text { curso }\end{array}$ & $15,27 \%$ & $11,45 \%$ & $30,53 \%$ & $24,43 \%$ & $16,79 \%$ \\
\hline $\begin{array}{l}\text { 2 Vou estudar para passar em } \\
\text { concurso público após terminar o } \\
\text { curso }\end{array}$ & $8,40 \%$ & $7,63 \%$ & $16,79 \%$ & $29,01 \%$ & $35,88 \%$ \\
\hline $\begin{array}{l}\text { 3 Pretendo seguir carreira } \\
\text { acadêmica }\end{array}$ & $18,32 \%$ & $6,87 \%$ & $25,95 \%$ & $27,48 \%$ & $19,08 \%$ \\
\hline
\end{tabular}

Fonte: Dados da Pesquisa 
Por fim, segue análise realizada conforme os resultados obtidos através do quadro 05.

\subsubsection{Pretensões Profissionais após a Conclusão do Curso}

Quanto as pretensões profissionais, 30,53\% dos estudantes se mostraram indiferentes ao se tornarem empreendedores, abrindo então um negócio próprio. Já, quanto a variável "2 Vou estudar para passar em concurso público após terminar o curso", 35,88\% dos respondentes afirma que concordam totalmente com esta proposição. Já, referente a afirmativa "3 Pretendo seguir carreira acadêmica", 27,48\% indicaram que concordaram. Assim, concluise que grande maioria procura optar por carreiras profissionais conquistadas por concursos públicos em razão da estabilidade inferida ao indivíduo.

\section{CONSIDERAÇÕES FINAIS}

Após analisados os resultados, e buscando compreender a cultura organizacional, por meio de dados através do modelo de questionário validado de Siqueira e Tamayo (2008), foi possível perceber que dentro das instituições de ensino privado há uma forte influência da institucionalização, buscando aproximar a visão dos alunos aos ideias e princípios cultuados pela universidade, tanto por uma questão mercadológica e isomórfica que busca garantir a sobrevivência destas organizações.

Assim, pode-se inferir que dentro da lógica das universidades privadas, o fator institucional repercute em grandes similaridades aos valores e princípios cultivados pelos acadêmicos. Em si, universidades privadas não oferecem apenar um serviço de ensino e de qualificação da mão de obra para o mercado de trabalho. Universidades privadas buscam a fidelização dos discentes a este nicho de mercado, ofertando mais do que qualidade sobre o seu serviço, mas sim, uma instituição ética frente a sociedade, de qualidade, acessibilidade e etc.

Por outro lado, tais questões não deixam de configurar uma questão estratégica mercadológica, que gira em torna da dinâmica das universidades privadas, onde é essencial transparecer uma visão positiva tanto por questões estruturais e profissionalizantes, bem como seguindo: princípios, qualidade, normas/valores e a cultura previamente estabelecida e internalizada. Mesmo que uma instituição de ensino superior privada possua um dever a cumprir com a sociedade física e jurídica, por meio da formação de indivíduos capacitados para atuar no mercado de trabalho de maneira ética, crítica e transparente, a instituição 
privada, como qualquer outra precisa para determinar a sua sobrevivência o mesmo fator que qualquer organização tradicional anseia e necessita, ou seja, capital (recursos financeiros)! É neste sentido que a fidelização do discente se torna essencial frente a teoria do isomorfismo, e a sobrevivência da instituição frente ao mercado.

O indivíduo ao ingressar em um curso de ensino superior privado em administração, acaba sendo fortemente influenciado pela dinâmica organizacional, onde busca usufruir do ensino, e ofertar a instituição a maximização do seu aprendizado, bem como, seguindo os valores, normas e crenças de boa conduta cultuadas pela instituição. Entretanto, as instituições de ensino privado não possuem características de fidelização máxima do discente, onde o mesmo pode optar em dar continuidade a seus estudos na instituição que desejar e for mais adequado frente ao seu ponto de vista. Também, foi possível perceber que alunos do curso de administração não possuem características empreendedoras, onde estes primeiramente buscam e priorizam a estabilidade almejando conquistar um emprego fixo, recorrendo em diversos casos, a concursos públicos, após a conclusão do ensino superior.

Neste sentido, como contribuições para este estudo, é possível descrever que inserido a dinâmica de qualquer organização, seja de ensino, como qualquer outra onde sua subsistência seja diretamente dependente do fator econômico, e lógica mercantilista e de mercado seguidamente se sobrepõem, pois, a necessidade primordial sobre a oferta dos serviços se encontram pautados sobre a satisfação do cliente.

\section{REFERENCIAS BIBLIOGRÁFICAS}

ABMES. Ensino superior privado: propostas para a educação brasileira. Brasília: Associação Brasileira de Mantenedoras do Ensino Superior, s/d.

BEZERRA, Alexandre M. A Gestão no Ensino Superior: Um desafio para educadores e administradores. Disponível em: < http://www.administradores.com.br/informe-se/artigos/agestao-no-ensino-superior-um-desafio-para-educadores-e-administradores/46635/>. Acesso em: 27/06/ 2015.

BRESSAN, Cyndia L. Mudança Organizacional: Uma Visão Gerencial. In: http://www.fae.edu/publicacoes/pdf/art_cie/art_25.pdf. 2004. Acesso em: 20/06/2015.

DIMAGGIO, P.J.; POWELL, W.W. A gaiola de ferro revisitada: isomorfismo institucional e racionalidade coletiva nos campos organizacionais. RAE Clássicos, [S. 1.], v. 45, n. 2, p. 7489, 2005.

FERREIRA, O.; FERREIRA FILHO, H, R, F; BELTRÃO, E, P. Isomorfismo, legitimidade e mitos na dinâmica organizacional da gestão universitária: como fatores institucionais que podem atuar no processo de mudanças em uma instituição de ensino superior privada na cidade de Belém-PA. Atlante. Cuadernos de Educación y Desarrollo, abril 2014.

Disponível em < http://atlante.eumed.net/gestao-universitaria/> 
HANANN, Michael; FREEMAN, John. Ecologia Populacional das Organizações. Revista de Administração de Empresas, v.45, n.3, p.70-91, jul./set. 2005.

INEP-Instituto Nacional de Estudos e Pesquisas. Education at a Glance: Indicadores OCDE 2012. Disponível em <http://download.inep.gov.br/acoes_internacionais/estatisti cas_educacionais/o cde/education_at_a_glance/eag2012_country_note_-_Brazil.pdf.> Acesso em: 01. Jun. 2015.

MACHADO-DA-SILVA, C. L.; FONSECA, V. S.; CRUBELLATE, J. M. Estrutura, agência e interpretação: elementos para uma abordagem recursiva do processo de institucionalização.

Revista de Administração Contemporânea, v. 9, p. 9-39, 2005. Edição Especial.

MINTO, L. W. A educação da "miséria": particularidade capitalista e educação superior no Brasil. 2011. 322f. Tese (Doutorado) - Programa de Pós-Graduação em Educação, Universidade Estadual de Campinas, Campinas, 2011.

PIMENTEL, T. D.; SOARES, A. de S.; LIMA, G. C. O. A (Des) constru- ção institucional do Mercado Central de Belo Horizonte. In: ENCONTRO DA ASSOCIAÇÃO NACIONAL DOS PROGRAMAS DE PÓS-GRADUAÇÃO EM ADMINISTRAÇÃO - ENANPAD, 30., Salvador, 2006. Anais... Rio de Janeiro: ANPAD, 2006. Acesso em: 24 jun. 2015.

QUEIROZ. F, C, B, P; Queiroz, J, V; hékis, H, R. CUSTOS DA QUALIDADE Uma ferramenta de gestão para as Instituições de Ensino Superior Privadas. Revista da FARN, Natal, v. 10, n. 1/2, p. 195-221, 2011.

RIBEIRO, D. A. Trajetória institucional da universidade brasileira: a UFBA como reflexo e modelo. 2011. Tese (Doutorado em Administração) - Núcleo de Pós-Graduação em Administração, Universidade Federal da Bahia, Salvador, 2011.

SIQUEIRA, M.M.M; TAMAYO, A. Medidas do comportamento organizacional: Ferramentas de diagnóstico e de gestão / Valores Organizacionais. Mirlene Maria Matias Siqueira (org.). - Porto Alegre : Artmed, 2008.

SGUISSARDI, V. A Universidade neoprofissional, heterônoma e competitiva. In: MANCEBO, D.; FÁVERO, Maria de Lourdes A. (Org.). Universidade: Políticas, avaliação e trabalho docente. São Paulo: Cortez, 2004.

TOLBERT, P. S.; ZUCKER, L. G. A institucionalização da teoria institucional. In: CLEGG, S. R.; HARDY, C.; NORDY, W. R. (Org.). Handbook de estudos organizacionais: modelos de análise e novas questões em estudos organizacionais. São Paulo: Atlas, 2010.

VASCONCELOS. A, F; Revendo Algumas Dimensões da Docência Com Professores Do Terceiro Grau. REAd - Edição 27 Vol. 8 No. 3, mai-jun 2002. 